PO028

\title{
CHROMATIC ADAPTATION EFFECTS AND LIMITS OF AMBIENT ILLUMINATION SPECTRAL CONTENT
}

\author{
Balazs Vince Nagy et al. \\ DOI 10.25039/x46.2019.PO028 \\ from \\ CIE x046:2019 \\ Proceedings \\ of the \\ 29th CIE SESSION \\ Washington D.C., USA, June 14 - 22, 2019 \\ (DOI 10.25039/x46.2019)
}

The paper has been presented at the 29th CIE Session, Washington D.C., USA, June 14-22, 2019. It has not been peer-reviewed by CIE.

\section{(C) CIE 2019}

All rights reserved. Unless otherwise specified, no part of this publication may be reproduced or utilized in any form or by any means, electronic or mechanical, including photocopying and microfilm, without permission in writing from CIE Central Bureau at the address below. Any mention of organizations or products does not imply endorsement by the CIE.

This paper is made available open access for individual use. However, in all other cases all rights are reserved unless explicit permission is sought from and given by the CIE.

CIE Central Bureau

Babenbergerstrasse 9

A-1010 Vienna

Austria

Tel.: +43 17143187

e-mail: ciecb@cie.co.at

www.cie.co.at 


\title{
CHROMATIC ADAPTATION EFFECTS AND LIMITS OF AMBIENT ILLUMINATION SPECTRAL CONTENT
}

\author{
B.V. Nagy ${ }^{1}$, Á. Urbin ${ }^{1}$, M. Dominek ${ }^{1}$, Á. Nyitrai ${ }^{2}$, L. Sipos ${ }^{2}$ \\ ${ }^{1}$ Department of Mechatronics, Optics and Engineering Informatics, Budapest University of \\ Technology and Economics, Budapest, HUNGARY, \\ 2 Department of Postharvest Science and Sensory Evaluation, Szent István University, \\ Budapest, HUNGARY \\ nagyb@mogi.bme.hu
}

DOI 10.25039/x46.2019.PO028

\begin{abstract}
The paper shows results on color discrimination in self-luminous and reflective visual tasks and in a food sample sensory testing application under different illumination chromaticities after adaptation. The results indicate lower color discrimination when the illumination chromatic content is unbalanced, i.e. further from the neutral white and specific issues at the blue dominated illumination. The results may be used for practical purposes in general illumination.
\end{abstract}

Keywords: color discrimination, tunable illumination, spectral masking

\section{Introduction}

Human chromatic visual photosensation is based on three basic primaries, the three types of cone photoreceptors (Young, 1802; Boynton, 1979; Hubel, 1988; Valberg, 1991). Despite this neural information sampling the input physical parameters for vision depend on the wavelength composition of the stimulus. Hence the understanding of the spectral power distribution (SPD) of the visual ambient is prioritized when addressing chromatic perception questions and when it comes to lighting effects, tunable SPD in ambient or target illumination is a handy tool for researchers (Mott, 2012; Ellis, 2014; Oh, 2014).

This applies to scientific investigation of chromatic adaptation, since color appearance is altered with the illumination chromatic properties (Brainard, 1997; Kuriki, 1997). The adaptation mechanisms (Boynton, 1979; Arend, 1991; Webster, 1996) of the visual system tend to compensate the altered input of the ambient with chromatic adaptation, although the possibility for complete compensation depends on the spectral content of the illumination (Kuriki, 1996). Studies have shown (Viénot et al., 2005; Nagy et al. 2013) that illumination with differing SPD but with similar CCT and/or chromaticity can affect color perception.

In our study we aimed to analyse color discrimination changes using psychophysical tools while adapting to various illumination spectra and we applied the results in a specific use case in the food industry.

The visual characteristics of the food products and different spectral ambients affect the other sensory characteristics (taste intensity, odor intensity, aroma attributes, texture attributes, etc.). The color can intensify or weaken the perceived intensity of foods, and it can generate expectations that influence the sensory perception. If the sensory testing is not based on visual evaluation, then it needs lighting conditions in which the color of the products does not influence the perception of other sensory characteristics (Spence, 2018).

\section{Methods}

The study was based on the application of different standard color discrimination methods for visual tests under varied spectral illumination. The adaptation illumination was realized in a spectrally tuneable light booth using five primaries of high intensity LEDs (red $-623 \mathrm{~nm}$, amber $-596 \mathrm{~nm}$, green $-527 \mathrm{~nm}$, blue $-460 \mathrm{~nm}$ and warm white). The booth was custom made so that human participants would have full field homogeneous stimulus of luminance level set to 26 $\mathrm{cd} / \mathrm{m}^{2}$ for all illumination conditions. 
Eighteen different spectral conditions were applied in the visual tests addressing human chromatic discrimination mixed by the control software of the LED primaries. The calculated u'v' coordinates of each illumination ambient are shown in Fig. 1 indicating the gamut of the illumination as the extremes (single LED illumination) were applied as well.

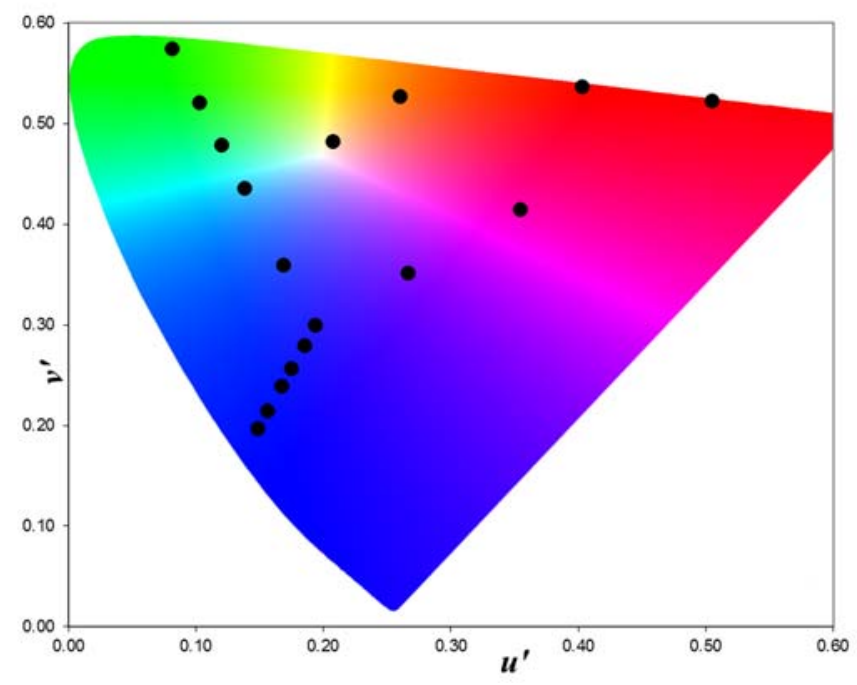

Figure 1 - Adaptation conditions used in the experiment created in the RGBAW light booth

The color discrimination tests to investigate human chromatic adaptation limits were the ellipse test of the Cambridge Research Systems' (CRS) Cambridge Color Test (CCT) and the Lanthony D-15d reflective test with desaturated samples. Sixteen participants with normal color vision and without visual problems took part in the color discrimination tests. Initially we applied three minutes of adaptation in each lighting condition prior to the test. The monitor based selfluminous test was applied behind the light booth, observed through a window within 8 degrees of visual angle to avoid direct screen reflections but to maintain the adaptation ambient in the rest of the visual field. Human color discrimination was tested around the white point of u'v' = $0.1977,0.4689$ in eight directions in the u'v' color space from the horizontal axis at intervals of $45 \mathrm{deg}$. The visual target was a chromatic Landolt-C stimulus made of pseudo-isochromatic patches in an achromatic background of equal average luminance as the stimulus (Mollon, 2000). The result was the threshold of color discrimination, which was calculated as the $10^{\wedge} 4$ times the $\Delta \mathrm{E}_{u^{\prime} v^{\prime}}$ in each direction in the color space with respect to the white point. Different to the original CRS test, we used the individual threshold values in our evaluation and not the fitted ellipse onto them.

The D15d reflective tests were applied within the light booth with the CCT test first and the D15d after. Here 15 patches had to be put in color order under each illumination condition. The Color Confusion Index $(\mathrm{CCl})$ was calculated from the ratio of the summed $\square \mathrm{E}_{\mathrm{Lab}}$ differences of the correctly ordered color patches and the one performed by each participant.

Beside the standard laboratory psychophysical test we designed an applied experiment using specific food samples for human sensory testing to induce masking and/or alteration of chromatic information of the food sample colors. The triangle difference test (ISO 4120:2004; ISO 16820:2004) was applied for testing the masking effect. Normal trichromats did ordering and grouping tests of food samples in different spectral ambients calculated specifically based on the transmission and reflection spectra of the samples measured by a transmission spectrophotometer. The goal of this test was to show the information disguise in case of food samples in judgement tests when following the ISO 8589:2007 standard. In order to ensure the reference conditions indicated in the standard the internal surface of the light booth was covered by grey diffuse material (Munsell N4) and D65 illumination was created.

The food samples consisted of 35 different green and black tea types (Camellia sinensis L.) in identical transparent glass sample tubes. The transmission and reflection spectra were measured and we observed that the differences between the samples were not spectrally 
identifiable, i.e. there was no specific wavelength range for differences between the samples, but the variations were in the whole visible spectrum. Thus the masking in these specific samples may not be done in one specific wavelength range. In order to see if the quasi monochromatic spectra of the RGBA LEDs may induce perceptual differences compared to the D65 illumination we applied two psychophysical tests for the food samples. The so called triangulation test was the one where three samples were presented the same time, two from the same sample and one different. The participant had to indicate the different sample. The other test was a pairing test where six sample pairs were mixed and the finding of the original pairs was the task. In both tests the number of errors were marked for evaluation.

\section{Results}

\subsection{Discrimination tests}

The self-luminous color discrimination tests indicate a representative variation depending on the ambient illumination chromaticity and the specific direction in the color space. Fig.2 shows two directions (indicated by the specific vectors) with characteristic changes in color discrimination. In all test directions in the color space we have found reduced color discrimination within the ambient illumination dominated by the blue region of the spectrum. At the same time the relative amount of suppression by the blue seems to be dependent on the test direction showing a larger effect on the yellow-blue axis and a lower on the red-green axis where all color ambient illuminations towards the gamut limits seem to reduce color discrimination. The inner part of the gamut show equal results when compared to the white ambient.
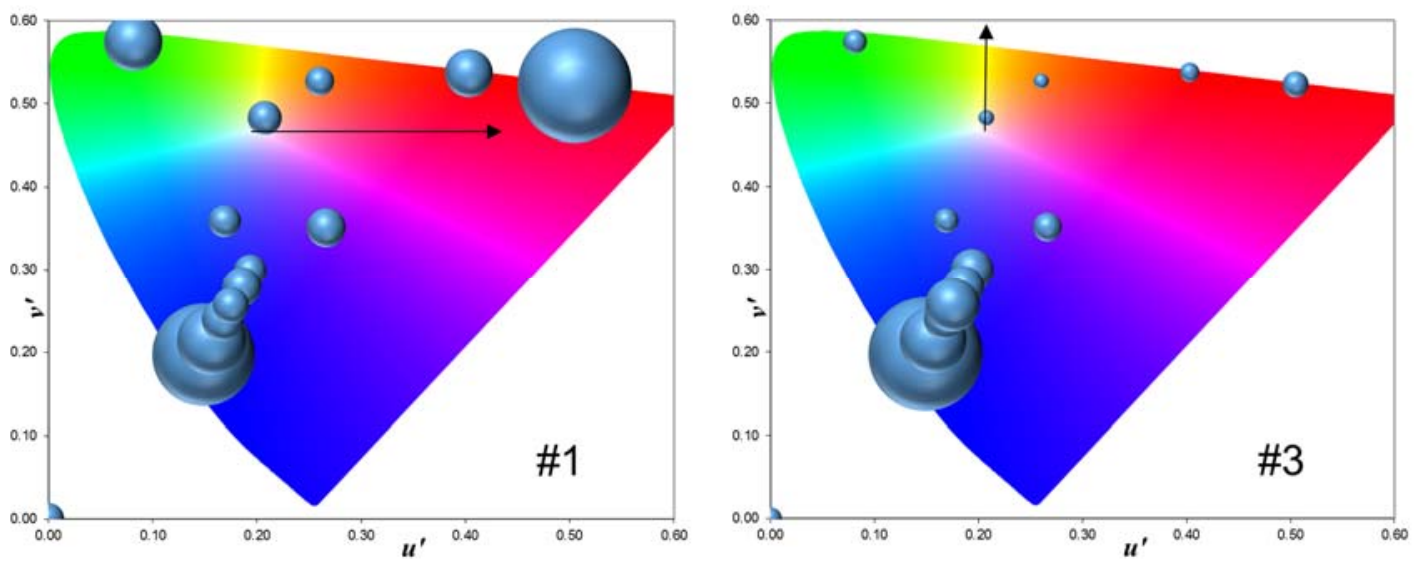

Figure 2 - Color discrimination thresholds of self-luminous tests under illumination types of different chromaticities. The size of the balls correlate with the threshold from the white point. \#1 shows typical example for color discrimination test along the redgreen axis with similarly large threshold for each quasi monochromatic ambient lights, while \#3 shows the test along the yellow-blue axis where the blue seems to dominate suppression in color discrimination.

The D15d test results were similar to those of the red-green axis of the self-luminous tests with relatively high error rates represented by the $\mathrm{CCl}$ at the edges of the gamut and lower error rates around the achromatic adaptation chromaticities. Fig. 3 shows the error levels at each ambient illumination. 


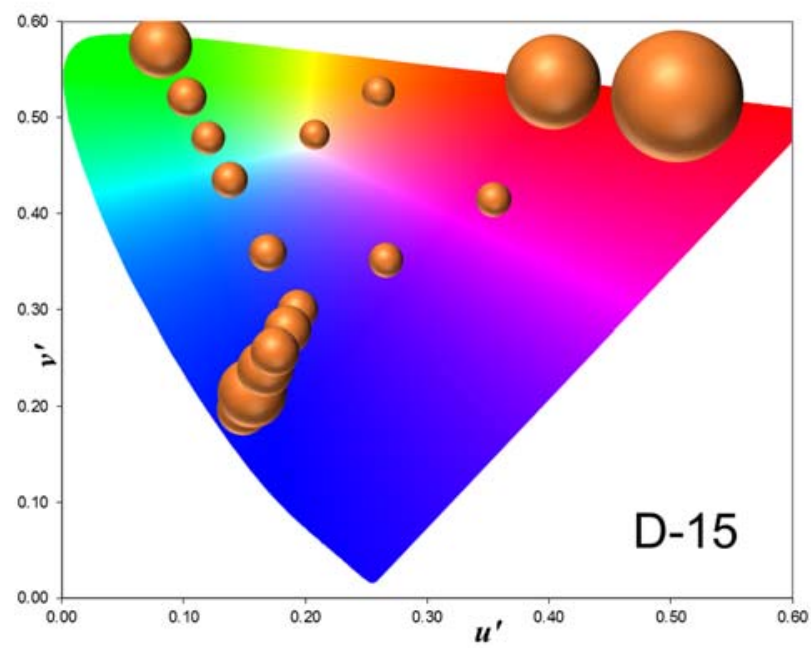

Figure 3 - Color Confusion Index levels calculated from the test results of the D15d test. The size of the balls correlate with the level of error in the ordering task.

\subsection{Food sample discrimination}

The triangle tests did not give significantly different results under the different illuminants. However we can observe a tendency towards a larger error rate under pure red and amber illumination where the transmission and reflection spectra of the specimen showed larger differences. Table 1 indicates the error rates at each test. We also observed that the time for decision when selecting the pairs of the samples increased when applying illumination different from D65. In case of the last sample pair (14-20) the small difference between the sample caused larger error rates under blue illumination.

Table 1 - Error count of the triangulation test when pairing food samples under each illuminant

\begin{tabular}{|l|l|l|l|l|l|}
\hline $\begin{array}{l}\text { Sample no. / } \\
\text { illuminant }\end{array}$ & D65 & R LED & G LED & B LED & A LED \\
\hline $11-15$ & 0 & 0 & 0 & 0 & 0 \\
\hline $3-4$ & 0 & 5 & 0 & 0 & 1 \\
\hline $2-12$ & 0 & 0 & 0 & 1 & 3 \\
\hline $1-9$ & 0 & 0 & 0 & 0 & 0 \\
\hline $7-19$ & 0 & 1 & 0 & 0 & 4 \\
\hline $14-20$ & 0 & 4 & 1 & 6 & 4 \\
\hline
\end{tabular}

\section{Discussion}

Considering all results we can state that adaptation to ambient illumination chromaticity has effect on color discrimination whether presented on self-luminous or in reflective visual tasks. We have seen that the more unbalanced the ambient illumination chromatic content the worse the color discrimination is. Thus one may indicate a range within the color space where the tolerance of color discrimination is comparable to that of well-balanced chromatic content (i.e. white) ambient. In case of the self-luminous stimulation we observed larger suppression by the bluish ambient when testing on the yellow-blue axis which may have an underlying physiological background regarding the low ratio of blue photoreceptors in humans. However further testing is need to confirm this or at least separate from a possible glare issue which is generally larger with lower wavelength light.

In the case of applying tunable light booth for food sensory testing the similar spectra in samples may not be adequate for spectral masking, however larger confusion and decision time may be introduced with extreme lighting conditions when compared to D65. In order to have effect of 
spectral masking one may use such in applications where larger spectral differences can be observed in the food samples and these are designated to specific wavelength ranges.

\section{Acknowledgments}

This paper was supported by the János Bolyai Research Scholarship of the Hungarian Academy of Sciences and by the ÚNKP-18-4 New National Excellence Program of the Ministry of Human Capacities (authors BVN and LS). Author ÁNy appreciates the support of the Food Science Doctoral School of theSzent István University.

\section{References}

AREND, LE, REEVES, A, SCHIRILLO, J, GOLDSTEIN, R, 1991. Simultaneous color constancy: papers with diverse Munsell values. J. Opt. Soc. Am. A 8. p661-672.

BOYNTON, RM 1979. Human Color Vision. New York: Holt, Rinehart and Winston.

BRAINARD, DH, BRUNT, WA, SPEIGLE, DM, 1997 'Color constancy in the nearly natural image. I. Asymmetric matches,' J. Opt. Soc. Am. A 14, 2091-2110

ELLIS, EV, GONZALEZ, EW, KRATZER, DA, MCEACHRON, DL, YEUTTER, G, 2014. Autotuning daylight with LEDs: sustainable lighting for health and wellbeing. In ARCC Conference Repository.

HUBEL, DH 1988. Eye, Brain, and Vision. New York: W. H. Freeman.

ISO 4120:2004 Sensory analysis -- Methodology -- Triangle test

ISO 8589:2007 Sensory analysis -- General guidance for the design of test rooms

ISO 16820:2004 Sensory analysis -- Methodology -- Sequential analysis

KURIKI, I, UCHIKAWA, I, 1996. Limitations of surface-color and apparent-color constancy. J. Opt. Soc. Am. A 13. p1622-1635.

KURIKI, I, MACLEOD, DIA, 1997. Chromatic adaptation aftereffects on luminance and chromatic channels, in John Dalton's Colour Vision Legacy, Taylor \& Francis, London p7382.

MOLLON, JD, REFFIN, JP, 2000. Hanook of the Cambridge Colour Test. London, UK: Cambridge Research Systems.

MOTT, MS, ROBINSON, DH, WALDEN, A, BURNETTE, J, RUTHERFORD, AS, 2012. Illuminating the effects of dynamic lighting on student learning. SAGE Open, 2(2)

NAGY, BV, BARBONI, MTS, OLIVEIRA, JG, VENTURA, DF, 2013. The effect of ambient illumination spectrum on visual performance. Proceedings of the CIE Centenary Conference, p72-75.

$\mathrm{OH}, \mathrm{JH}$, YANG, SJ, DO, YR, 2014. Healthy, natural, efficient and tunable lighting: four-package white LEDs for optimizing the circadian effect, color quality and vision performance. Light: Science \& Applications, 3(2), e141.

C SPENCE, 2018. Background colour and its impact on food perception and behaviour. Food Qual. and Prefer. 68 (2) 156-166.

VALBERG, A \& LEE, BB Eds. 1991. From Pigments to Perception. London: Plenum Press.

VIÉNOT, F, DURAND, ML, MAHLER, E, 2009. The effect of LED lighting on performance, appearance and sensation. Light and Lighting CIE conference, Budapest

WEBSTER, MA, 1996. Human color perception and its adaptation. Computation in Neural Systems 7: 587-634.

YOUNG, T, 1802. Bakerian Lecture: On the Theory of Light and Colours. Phil. Trans. R. Soc. Lond. 92:12-48. 